\title{
MAPEAMENTO DE FRAGILIDADE AMBIENTAL DO PARQUE NACIONAL DA SERRA DE ITABAIANA/SE
}

\author{
Luan Lacerda Ramos ${ }^{(a)}$, Alexandre Herculano de Souza Lima ${ }^{(b)}$, Lucas Marcone dos Santos ${ }^{(\mathrm{c})}$, \\ Ronaldo Missura $^{(\mathrm{d})}$ \\ (a) Departamento de Geografia/UFS, Universidade Federal de Sergipe, luan_ramos1@ @ hotmail.com \\ (b) Departamento de Geografia/UFS, Universidade Federal de Sergipe, dandefish@ hotmail.com \\ (c) Departamento de Geografia/UFS, Universidade Federal de Sergipe, lcsmarcone@ gmail.com \\ (d) Departamento de Geografia/UFS, Universidade Federal de Sergipe, ronaldomissura@ gmail.com
}

\section{Eixo: GEOTECNOLOGIAS E MODELAGEM ESPACIAL EM GEOGRAFIA FÍSICA}

\begin{abstract}
RESUMO
O principal objetivo do presente trabalho consistiu em elaborar o mapa de fragilidade ambiental do Parque Nacional da Serra de Itabaiana localizado em Sergipe. O uso deste mapeamento consiste em identificar áreas com potenciais riscos de ocorrência de erosões, inundações, instabilidades de terrenos, movimentos de massas além das potencialidades e fragilidades naturais oriundas do uso e ocupação da área em questão. Os produtos gerados pela pesquisa consistiram do mapa de declividade, de classes de solo, de dissecação do relevo, de uso da terra e cobertura vegetal e, por fim, o mapa de fragilidade ambiental, constatando-se que os índices de declividade e de dissecação do relevo colocaram-se enquanto fatores determinantes na culminação do risco ambiental.
\end{abstract}

Palavras chave: Serra de Itabaiana, Fragilidade Ambiental, Sistema de Informação Geográfica (SIG), Geoprocessamento.

\section{Considerações Iniciais}

O Mapa de Fragilidade Ambiental (MFA) do Parque Nacional da Serra de Itabaiana (PNSI) é oriundo da produção acadêmica e profissional dos alunos que estiveram envolvidos com o projeto. $\mathrm{O}$ fruto deste trabalho foi convertido em relatório apresentado à disciplina de Estágio Obrigatório I da Universidade Federal de Sergipe (UFS) sob orientação do professor Dr. Ronaldo Missura.

O objetivo primordial da realização deste mapeamento tem sua gênese no interesse dos discentes em aplicar o conhecimento teórico e prático adquiridos ao longo do curso de geografia da UFS. Concomitante a este propósito, os alunos buscaram identificar em seu recorte de estudo as áreas que apresentam podential risco de fragilidade ambiental no Parque Nacional da Serra de Itabaiana e de sua zona de amortecimento, localizadas no estado de Sergipe (SE).

O conceito de fragilidade ambiental adotado neste estudo baseia-se em uma perspectiva geomorfológica, levando em consideração tanto os aspectos naturais da paisagem como a intervenção antrópica. Os estudos geomorfológicos são imprescindíveis para a análise de eventos como erosões, inundações, instabilidades de terreno, movimentos de massas, além de permitir o auxilio na 


\section{OS DESAFIOS DA GEOGRAFIA FÍSICA NA FRONTEIRA DO CONHECIMENTO \\ Instituto de Geociências - Unicamp \\ Campinas - SP \\ 28 de Junho à 02 de Julho de 2017}

identificação das potencialidades e fragilidades naturais dos terrenos conforme os seus variados usos e ocupações (SANTOS e SOBREIRA, 2008).

O Parque Nacional da Serra de Itabaiana é abrangido territorialmente pelos municípios de Areia Branca, Iatabaiana, Campo do Brito, Itaporanga D'ajuda, e Laranjeiras. A zona de amortecimento da serra em questão, por sua vez, exerce influência sobre os limites territoriais destes mesmos municípios além dos municípios de Moita Bonita, Malhador, Riachuelo, Nossa Senhora do Socorro, São Cristóvão, Lagarto e São Domingos. A extenão areal do PNSI é de, aproximadamente, $80,24 \mathrm{~km}^{2}$ e sua zona de amortecimento compreende a extensão próxima de 931,57 km² (Figura 1).

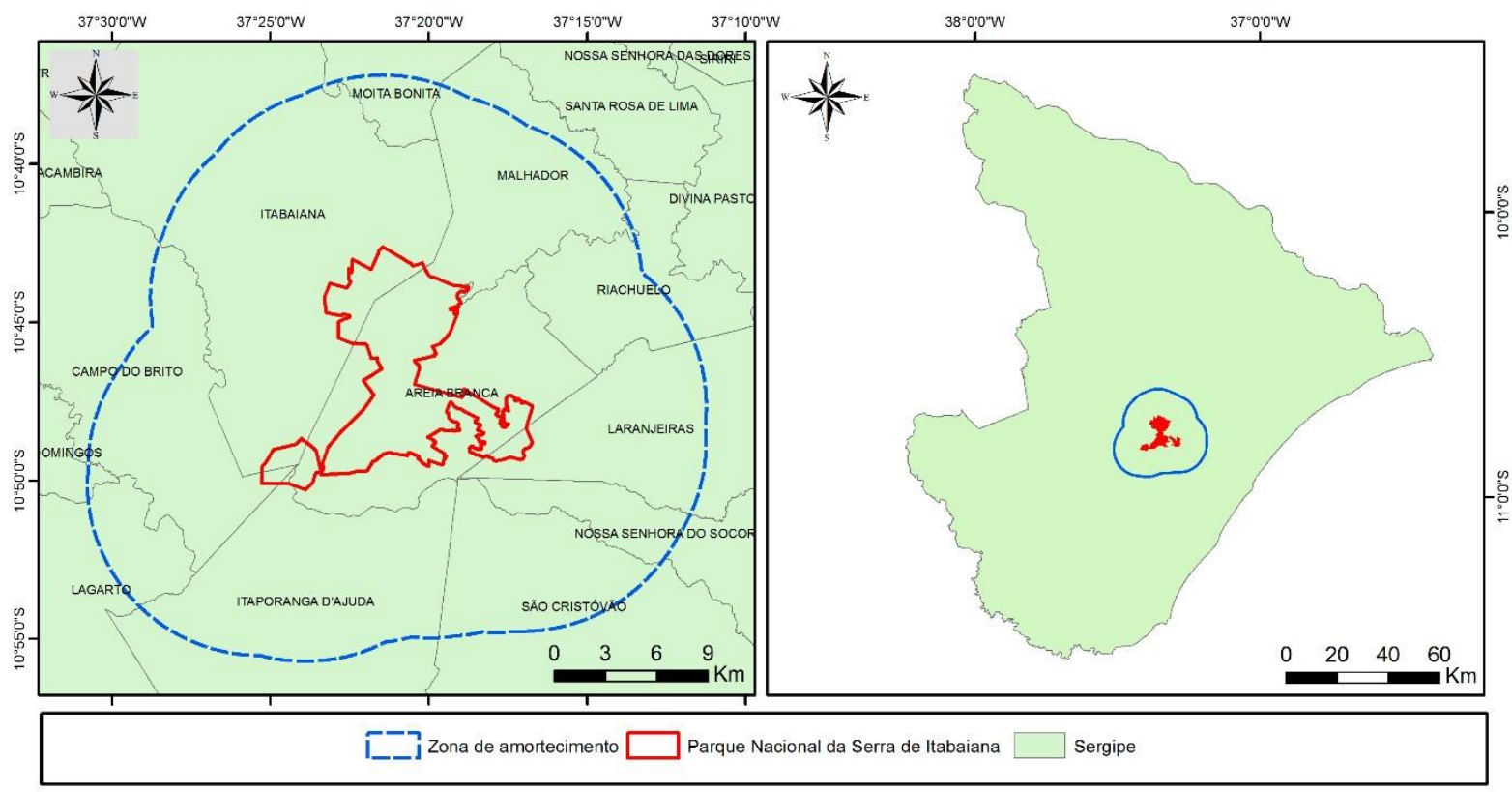

Figura 1: Localização da àrea de estudo

\section{Conceitos e definições}

O Parque Nacional da Serra de Itabaiana (PNSI) foi legitimado a partir da instauração do decreto $\mathrm{s} / \mathrm{n}$ de 15 de janeiro de 2005, que delimita sua extensão e estabelece o objetivo básico de preservação do ecossistema natural existente bem como a autorização da realização de pesquisas científicas e o desenvolvimento de atividades de educação ambiental e de turismo ecológico.

Por sua vez, o limite da zona de amortecimento de que tratamos no tópico precedente foi estabelecido pela lei $\mathrm{n}^{\circ}$ 99.274/70, determinando sua extensão ao raio de des quilômetros a contar dos limites compreendidos do Parque Nacional. 


\section{Técnicas e procedimentos}

À devida concretização do trabalho, os discentes, juntamente com seu orientador, dividiram as tarefas a serem operadas em três momentos. O primeiro momento consistiu do emprego da metodologia de revisão bibliográfica em que foram abarcadas principalmente as leituras de ROSS (1994), Tricart (1977) e Donha et al (2003), além do decreto s/n de 15 de janeiro de 2005 e da lei $n^{\circ}$ 99.274/70, em que parte dessas leituras foram apresentadas no tópico precedente. O segundo momento foi dividido em outras duas fases: inicialmente operou-se a busca pelos arquivos e dados a serem manipulados no Sistema de Informação Geográfica (SIG) ArcGIS 10.3 e, a segunda fase, compreendeu a manipulação propriamente dita desses dados e informações. O terceiro e último momento refere-se à análise dos produtos obtidos ao longo da operação do referido trabalho.

Os dados utilizados foram obtidos em órgãos oficiais tais como o Institudo Brasileiro de Geografia e Estatística (IBGE), o Instituto Chico Mendes de Conservação da Biosiversidade (ICMBio) e Institudo Nacional de Pesquisas Espaciais (INPE). O IBGE e o ICMBio forneceram os dados vetoriais utilizados para a espacialização da abrangência da área de estudo contemplando os municípios e o recorte do PNSI. No banco de dados ofertado pelo projeto TOPODATA, buscou-se o dado em raster do modelo digital de elevação.

O método utilizado para a geração final do MFA foi baseado nos estudos e procedimentos propostos por ROSS (1994). Deste modo, todos os elementos apresentados nos mapas utilizados para a composição do trabalho final (declividade; classes de solo; uso e ocupação do solo; dissecação) receberam valores que expressam o grau de fragilidade ambiental. Para a realização da concatenação final, a todos os resultados obtidos nos mapas foram aplicados cinco valores que expressam a hierarquia destes graus, sendo eles: 1 - Muito Baixa. 2 - Baixa; 3 - Média; 4 - Forte; 5 - Muito Forte.

Como o modelo digital de elevação foi amplamente utilizado para a concretização deste trabalho, seu tratamento foi inevitável. Assim, uma vez obtidas as devidas cartas que abrangiam a área de estudo, os discentes fizeram a composição do mosaico destas imagens. A partir dessa composição, a ferramenta stract by mask foi utilizada com o propósito de limitar as imagens do modelo digital de elevação somente à área de estudos que contempla o PNSI e sua zona de amortecimento que foi estabelecida pelo software a partir da aplicação da ferramenta buffer. Foi ainda aplicada sobre o modelo digital de elevação procedimentos de reprojeção para que o mesmo pudesse ser utilizado em sistema de coordenadas projetadas, que no caso em específico foi o datum SIRGAS 2000 na projeção UTM zona $24 \mathrm{~S}$. 


\section{OS DESAFIOS DA GEOGRAFIA FÍSICA NA FRONTEIRA DO CONHECIMENTO Instituto de Geociências - Unicamp \\ Campinas - SP \\ 28 de Junho à 02 de Julho de 2017}

O mapa de declividade classificado foi elaborado a partir do modelo digital de elevação. Neste procedimento, os discentes utilizaram a ferramenta slope. Os índices de fragilidade ambiental atribuídos aos graus de declividade foram classificados segundo ROSS (1994), conforme tabela 1.

Tabela I: Categorias de fragilidade segundo o grau da declividade

\begin{tabular}{|c|c|}
\hline \multicolumn{2}{|c|}{ CATEGORIAS HIERÁRQUICAS } \\
\hline Muito Fraca & até $6 \%$ \\
\hline Fraca & de 6 a $12 \%$ \\
\hline Média & de 12 a $20 \%$ \\
\hline Forte & de 20 a $30 \%$ \\
\hline Muito Forte & acima de $30 \%$ \\
\hline
\end{tabular}

O dado vetorial para elaboração do mapa de classes de solos foi obtido através da Empresa Brasileira de Pesquisa Agropecuária (EMBRAPA). O mesmo procedimento de recorte operado no modelo digital de elevação, porém com o uso da ferramenta clip, foi utilizado para a delimitação da área das classes de solos. Uma vez que este recorte estava efetivado, os discentes converteram este dado vetorial para o tipo raster, pelo fato de que a composição final do trabalho só poderia ser realizada se todos os demais arquivos também estivessem neste formato. A partir desta conversão e com a utilização da ferramenta reclassify, pôde-se categorizar cada uma das classes de solo de acordo com as cinco classes propostas por ROSS (1994) e apresentados na tabela 2.

Tabela II: Grau de fragilidade segundo as classes de solo

\begin{tabular}{|c|c|c|}
\hline TIPOS DE SOLO & ANTIGA CLASSIFICAÇÃo & FRAGILIDADE \\
\hline Argissolo & Podzólico Vermelho Amarelo & 3 \\
\hline Chernossolo & Brunezim Avermelhado & 3 \\
\hline Latossolo & Latossolo Vermelho Amarelo & 2 \\
\hline Luvissolo & Podzólico Vermelho Amarelo Equivalente Eutrófico & 3 \\
\hline \multirow{2}{*}{ Neossolo } & Solos Aluviais & 4 \\
\cline { 2 - 3 } & Solos Litólicos Eutróficos Distróficos & 5 \\
\hline Planossolo & Planossolo & 4 \\
\hline Vertissolo & Solos Hidromórficos & 5 \\
\hline
\end{tabular}

Para a composição do mapa de dissecação do relevo foi gerada uma malha regular com quadriculas medindo 1000 × 1000 metros. Foram transferidas as informações de altitude mínima, média e alta para cada quadricula e aplicada a seguinte fórmula proposta por EVANS (1972): 


\section{OS DESAFIOS DA GEOGRAFIA FÍSICA NA FRONTEIRA DO CONHECIMENTO Instituto de Geociências - Unicamp$$
\text { Campinas - SP }
$$ \\ 28 de Junho à 02 de Julho de 2017}

$\mathrm{d}=(\mathrm{z}-\mathrm{z}(\min )) /(\mathrm{z}(\max )-$

$\mathrm{z}(\min ))$ Sendo: $\mathrm{d}=$

dissecação; $\mathrm{z}=$ altitude.

Para os dados dissecação horizontal optou-se por utilizar a densidade de drenagem onde foi feita a relação entre a área de cada quadrícula e o comprimento dos canais englobados por estas. O grau de fragilidade segundo a dissecação também foi estabelecido conforme metodologia de ROSS (1994), no entanto o autor atribui os graus de fragilidade para dimenssões interfluviais, logo para a resolução desta problemática foram associados graus de fragilidade à classificação de densidade de drenagem proposta por Villela e Mattos (1975) conforme a descrição contida na tabela 3.

Tabela III: Grau de fragilidade segundo a dissecação horizontal (densidade de drenagem).

\begin{tabular}{|c|c|c|}
\hline CLASSIFICAÇÃO & DENSIDADE DE DRENAGEM & GRAU DE FRAGILIDADE \\
\hline Bacias com drenagem pobre & $<0,5 \mathrm{Km} / \mathrm{Km}^{2}$ & 1 \\
\hline Bacias com drenagem regular & $\geq 0,5 \mathrm{Km} / \mathrm{Km}^{2} \mathrm{a}<1,5 \mathrm{Km} / \mathrm{Km}^{2}$ & 2 \\
\hline Bacias com drenagem boa & $\geq 1,5 \mathrm{Km} / \mathrm{Km}^{2} \mathrm{a}<2,5 \mathrm{Km} / \mathrm{Km}^{2}$ & 3 \\
\hline Bacias com drenagem muito boa & $\geq 2,5 \mathrm{Km} / \mathrm{Km}^{2} \mathrm{a}<3,5 \mathrm{Km} / \mathrm{Km}^{2}$ & 4 \\
\hline Bacias excepcionalmente bem drenadas & $\geq 3,5 \mathrm{Km} / \mathrm{Km}^{2}$ & 5 \\
\hline
\end{tabular}

De posse do calculo da dissecação horizontal e dissecação vertical, foi feita uma concactenação entre os dois índices para obtenção dos dados de dissecação do relevo e assim associá-los aos respectivos graus de fragilidade conforme a tabela 4 , onde os algarismos da esquerda representam a dissecação vertical e os algarismos da direita a dissecação horizontal.

Tabela IV: Categorias hierárquicas da matriz de dissecação do relevo.

\begin{tabular}{l|l}
\hline \multicolumn{1}{c|}{ Fragilidade } & \multicolumn{1}{|c}{ Índice de dissecação na matriz } \\
\hline 1 - Muito baixa & 11 \\
2 - Baixa & $12,21,22$ \\
3 - Média & $13,23,31,32,33$ \\
4 - Alta & $14,24,34,41,42,43,44$ \\
5 - Muito alta & $15,25,35,45,51,52,53,54,55$ \\
\hline
\end{tabular}

O mapa de uso da terra e cobertura vegetal foi feito a partir de uma classificação supervisionada de imagem de satélite. A imagem utilizada foi obtida através do sítio do Instituto Nacional de Pesquisas Espaciais (INPE). Optou-se por fazer o download de imagens das bandas 2, 3, 4 e 8 do sensor OLI do Landsat 8 e posteriormente feita uma composição colorida $(4,3,2)$ e por fim uma fusão com a banda 8 
para se obter uma melhora na resolução espacial. As informações obtidas foram processadas e classificadas segundo a tabela 5 proposta por ROSS (1994).

Tabela V: Grau de fragilidade segundo o uso e ocupação do solo

\begin{tabular}{lcc}
\hline \multicolumn{1}{c}{ Tipos de Cobertura Vegetal } & $\begin{array}{c}\text { Grau de } \\
\text { Proteção }\end{array}$ & Código de fragilidade \\
\hline $\begin{array}{l}\text { Florestas/ Matas Naturais/ Florestas Cultivadas com biodiversidade } \\
\begin{array}{l}\text { Formacões arbustivas naturais com extrato herbáceo denso mata } \\
\text { secundária, capoeira densa, pastagem cultivada com baixo pisoteio, cultivo } \\
\text { de ciclo longo como o cacau }\end{array}\end{array}$ & Muito Alta \\
$\begin{array}{l}\text { Cultivo de ciclo longo em curvas de nível, pastagem com baixo pisoteio, } \\
\text { silvicultura de eucalipto com sub bosques de nativa }\end{array}$ & Média & 4 \\
$\begin{array}{l}\text { Cultivo de ciclo longo em baixas densidades café, laranja com solo exposto } \\
\text { entre ruas, culturas de ciclo curto arroz, soja e milho com cultivos em } \\
\text { curva de nível }\end{array}$ & Baixa \\
$\begin{array}{l}\text { Área desmatada e queimada recentemente, solo exposto por gradeação, } \\
\text { ao longo de caminhos e estradas, terraplagem, culturas de ciclo curto sem } \\
\text { práticas conservacionistas }\end{array}$ & Muito Baixa \\
\hline
\end{tabular}

Para obtenção do MFA foi aplicada uma técnica de sobreposição ponderada, com os quatro mapeamentos elaborados até então usando a ferramenta weighted overlay. Foram aplicados nesta fase uma influência de $25 \%$ para cada mapa sobre o produto final.

\section{Resultados e discussão}

A mapa de declividade apresentou os mais altos gaus de fragilidade ambital associados aos topos das serras do PNSI, com destaque para própria Serra de Itabaiana que possuem as áreas com maiores declividades mapeadas. No setor ao noroeste da serra as declidades são predominantemente planas, logo constatou-se grau de fragilidade muito baixo, outros setores ao leste e ao sudeste também apresentaram o mesmo grau. Nas meias encostas das serras, na porção sul, central e sudoeste da área de estudo as declividades encontradas variaram desde muito baixas até as fortes, sobressaindo-se sobre os demais, o grau de fragilidade médio. 


\section{OS DESAFIOS DA GEOGRAFIA FÍSICA NA FRONTEIRA DO CONHECIMENTO Instituto de Geociências - Unicamp Campinas - SP \\ 28 de Junho à 02 de Julho de 2017}

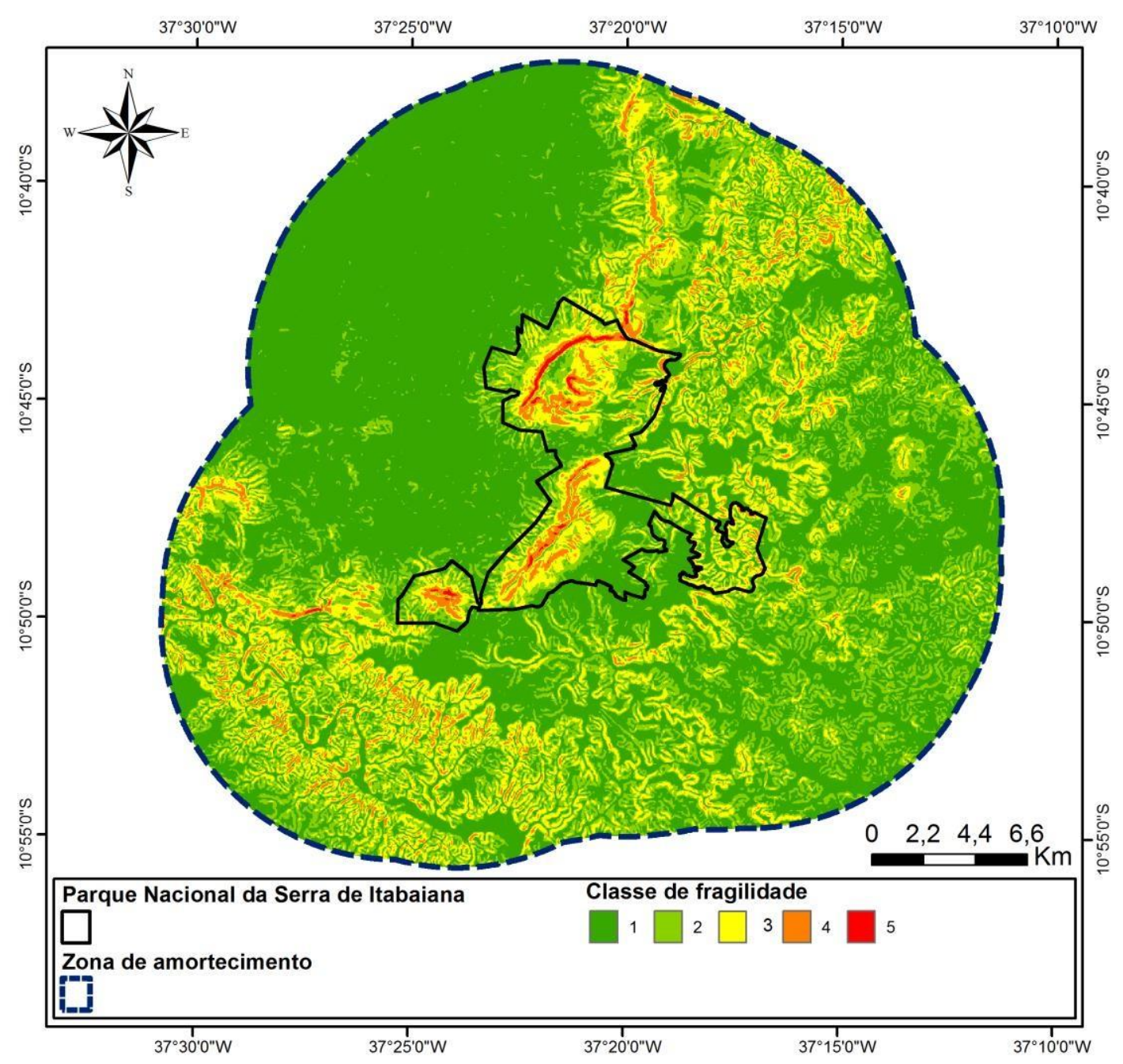

Figura 2: Mapa de declividade

Para os dados de fragilidade de classes de solo não foram encontradas áreas que compreendessem o grau muito baixo, apenas na porção sudoeste foram detectadas pontualmente fragilidades baixas associadas aos latossolos. Os médios índices de fragilidade recobriram a maior parte da área de estudo, estando relacionados a variadas classes de solo. Os índices altos se concentraram com maior expressividade na porção noroeste devido a influência dos planossolos. Nas proximidades dos maciços residuais no caso dos neossolos e ao redor do leito de canais situados no sudeste da área de estudo no caso dos vertissolos, evidenciaram-se áreas de fragilidade ambiental muito alta. 


\section{OS DESAFIOS DA GEOGRAFIA FÍSICA NA FRONTEIRA DO CONHECIMENTO Instituto de Geociências - Unicamp Campinas - SP \\ 28 de Junho à 02 de Julho de 2017}

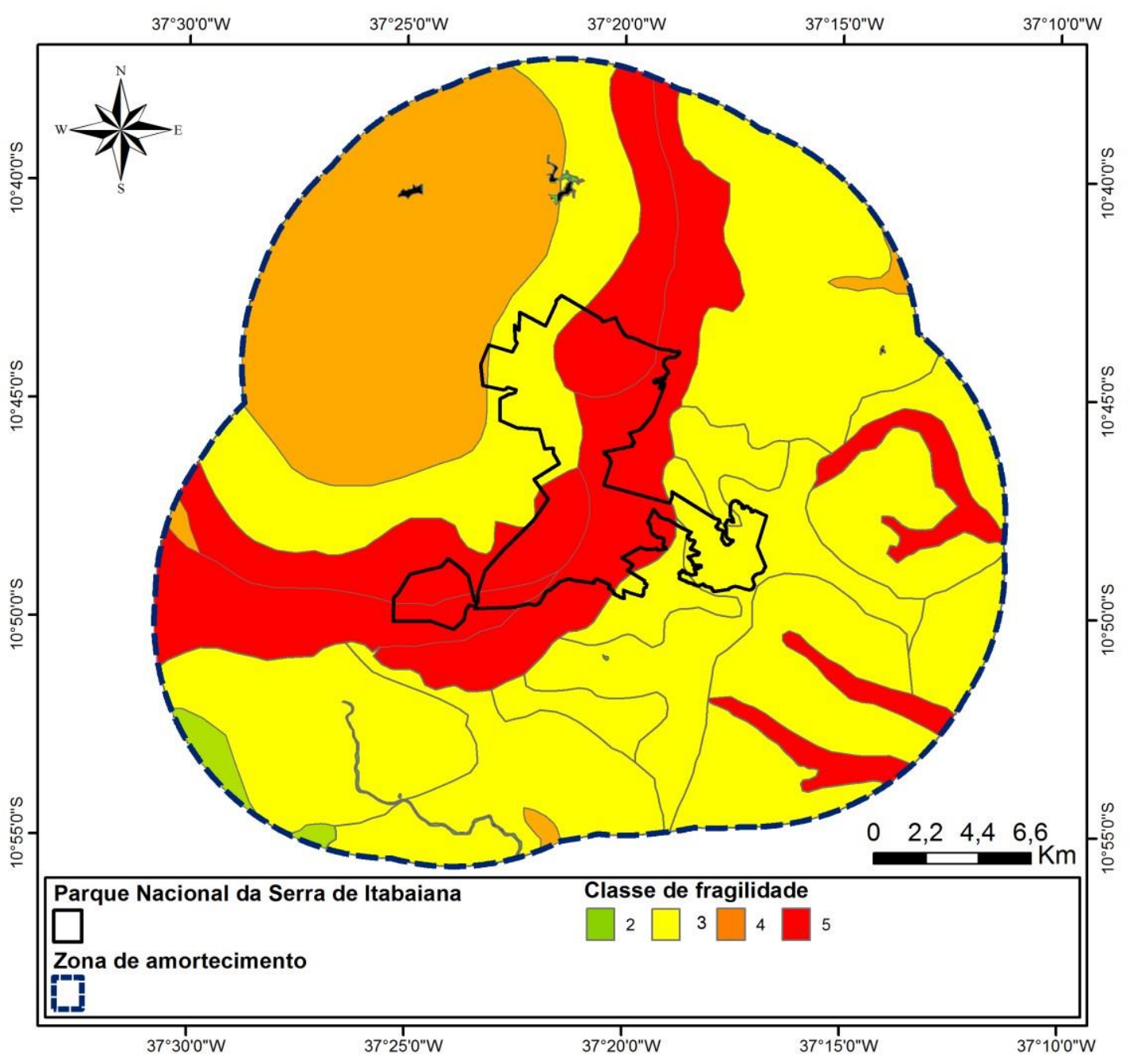

Figura 3: Mapa de classes de solo

O mapa de dissecação do relevo apresentou apenas aréas pontuais de fragilidade muito alta, onde se combinaram os altos graus de dissecação horizontal e vertical, estando estas áreas situadas na face noroeste da Serra de Itabaiana. A predominância evedienciada foi das classes baixa e muito baixa. 


\section{OS DESAFIOS DA GEOGRAFIA FÍSICA NA FRONTEIRA DO CONHECIMENTO Instituto de Geociências - Unicamp Campinas - SP \\ 28 de Junho à 02 de Julho de 2017}

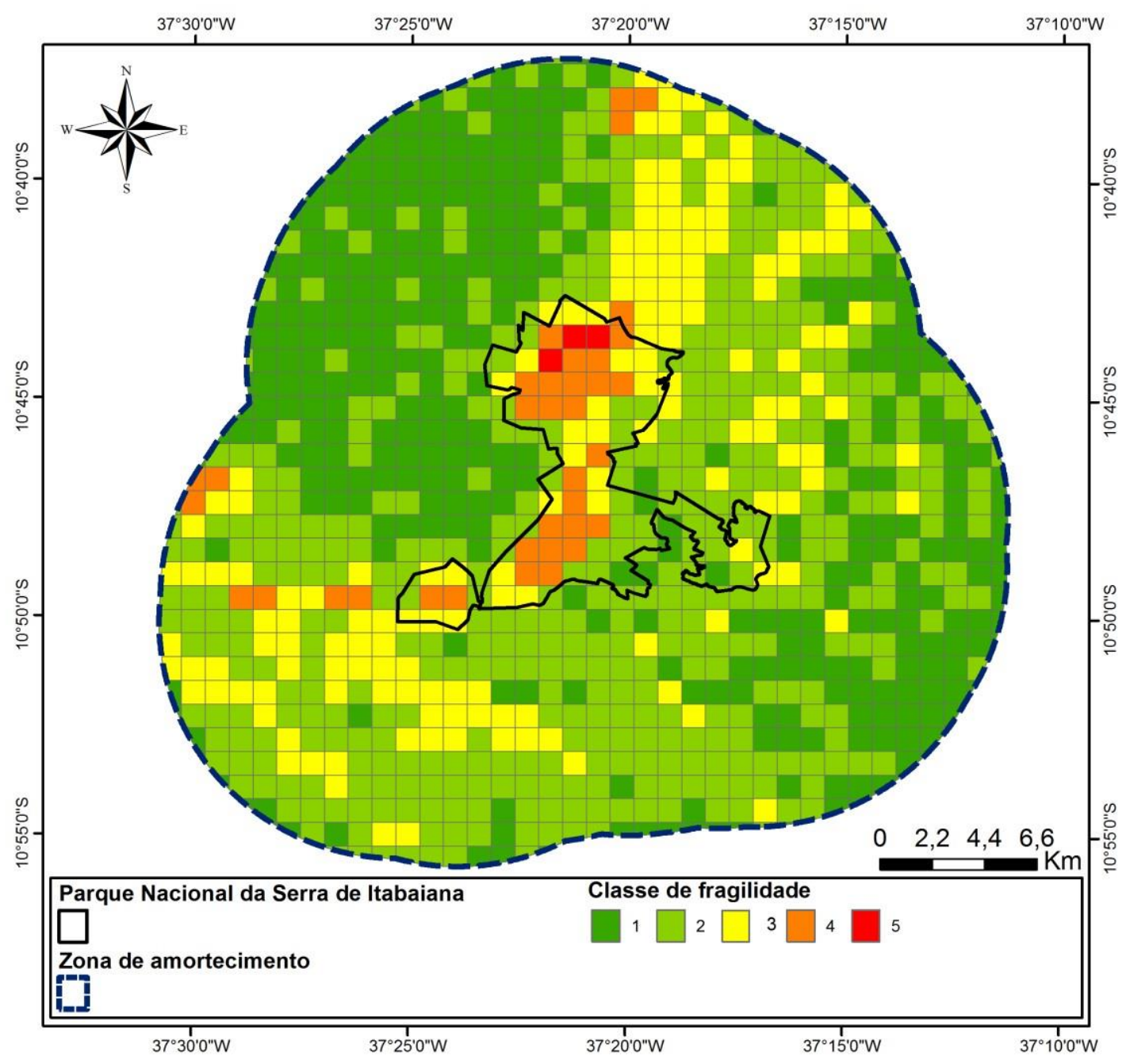

Figura 4: Mapa de dissecação do relevo

No mapa de uso da terra as fragilidades ambientais reconhecidas foram as mais heterogêneas dentre todos os mapeamentos desta pesquisa. As fragilidades muito altas encontradas estão relacionadas aos solos expostos, as rodovias e as sedes municipais dos municípios de Itabaiana, Areia branca e Malhador. As fragilidades altas estão associadas a áreas de pastagem. As fragilidades médias estão pricipalmente associadas a certos tipos de culturas. As fragilidades baixas foram encontradas onde há a presença de vegetação gramínea e arbustiva. As fragilidade muito baixas em grande parte situadas dentro do PNSI, estão relacionadas a vegetação densa de porte arbustivo.

O mapa de fragilidade ambiental revelou que o grau de fragilidade muito baixa é praticamente inespressivo na área de estudo, contabilizando $0,13 \mathrm{Km}^{2}$ e $0,01 \%$ do total. Apesar de nos mapas de declividade, dissecação do relevo e uso do solo haverem nitidamente áreas com interseção de fragilidade muito baixa, as fragilidade dos solos na área de estudo são predominantemente no mínimo médias, o que faz com que o grau de fragilidade em questão seja intensamente reduzido. 

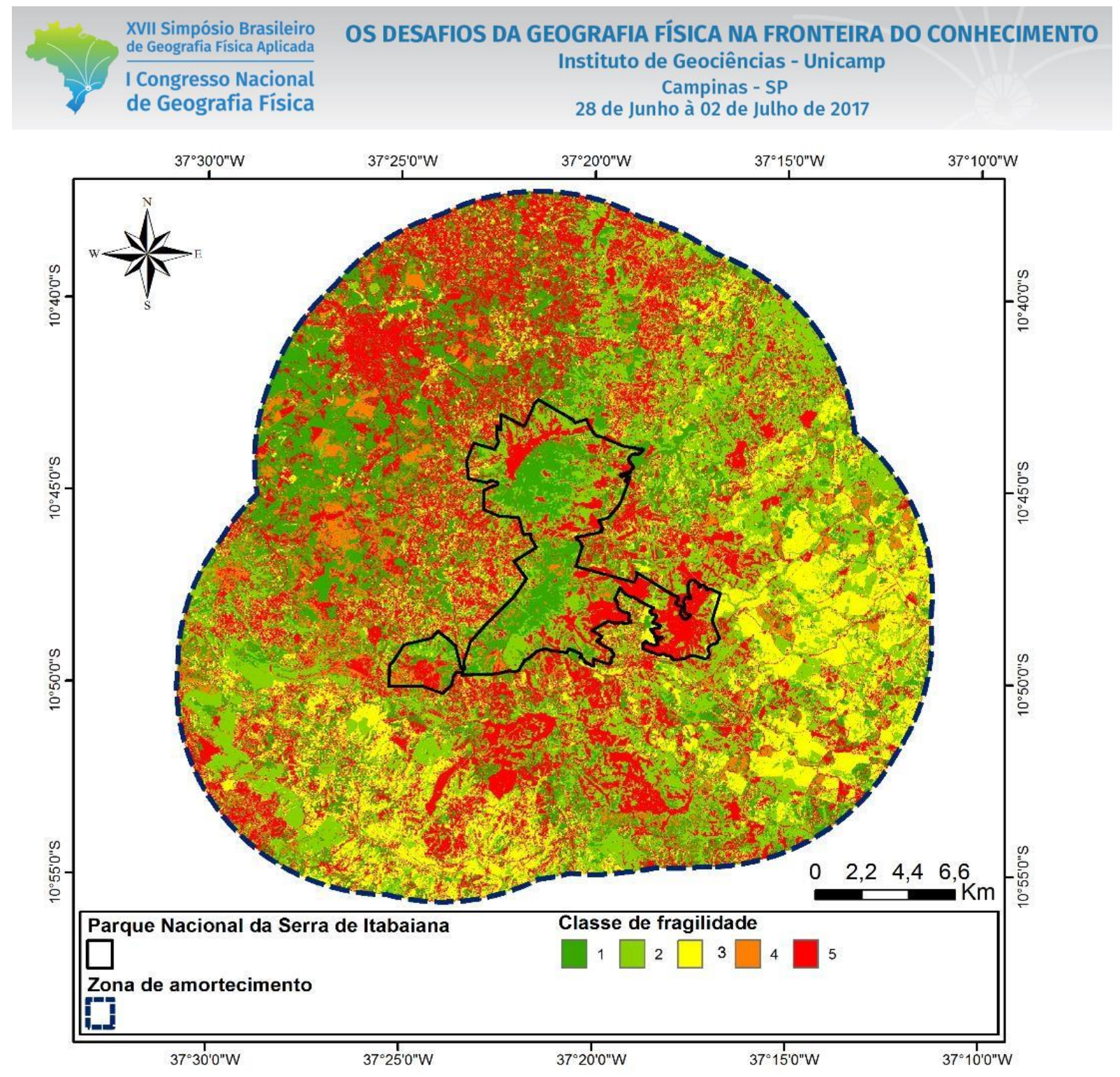

Figura 5: Mapa de classe de fragilidade

As grandes classes de fragilidade dominantes foram os graus baixo e médio, contablizaram 371,6

$\mathrm{Km} / \mathrm{Km}^{2}$ e 488,98 Km/Km² alcançadas principalmente devido a combinação do mapa de uso da terra e do mapa de declividade, pois foram os produtos gerados previamente que mais apresentaram variações de fragilidade.

A classe de alta fragilidade em particular se concentrou em uma área onde ocorrem solos com fragilidade muito alta, porém com declividades e dissecações médias, gerando assim um meio termo entre estes dois graus de fragilidade. Esta classe apresentou um formato semi-circular que acompanha os neossolos e as serras os maciços residuais do PNSI, contabilizando uma área $62,84 \mathrm{Km} / \mathrm{Km}^{2}$, representando $6,8 \%$ da área de estudo.

O grau de fragilidade muito alto constatado ocorreu principalmente em dois setores, um nas vertentes da Serra de Itabaiana orientadas para o noroeste e outro próximo ao topo da Serra da Cajaíba. Este 


\section{OS DESAFIOS DA GEOGRAFIA FÍSICA NA FRONTEIRA DO CONHECIMENTO \\ Instituto de Geociências - Unicamp \\ Campinas - SP \\ 28 de Junho à 02 de Julho de 2017}

grau se manifestou nestas área devido aos altos índices de declividade e dissecações do relevo que variam de alta a muito alta.

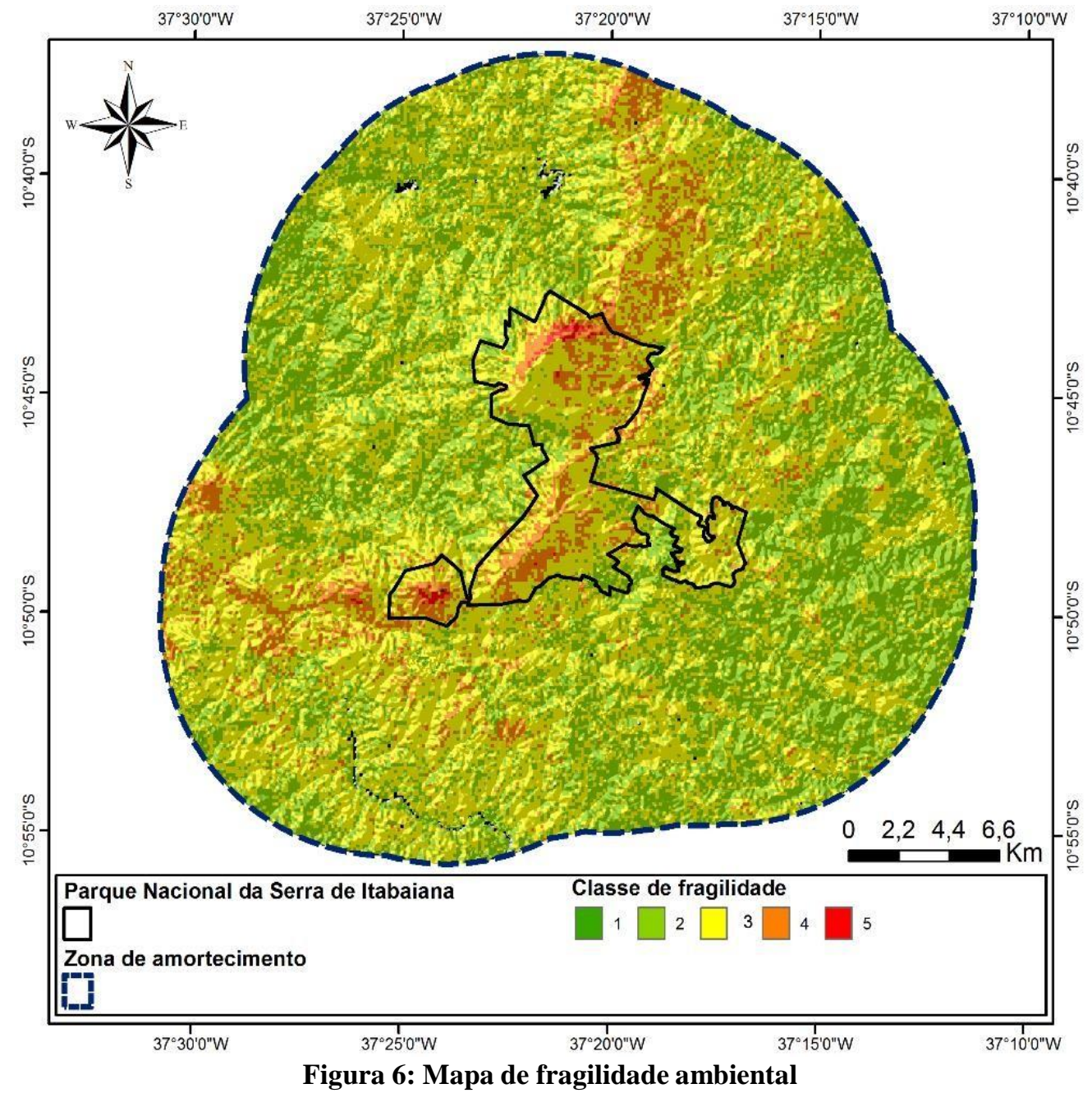

\section{Considerações finais}

O mapa de fragilidade abmiental elucidou nitidamente as áreas susceptíveis a pertubações ambientais de acordo com uma perspectiva geomorfológica, ratificando a importância da unidade de conservação estudada e de sua zona de amortecimento, permitindo assim o fornecimento de informações relevantes para a gestão do parque e para futuros estudos que venham a ser deselvovidos na área.

\section{Bibliografia}

Donha, A. G.; Souza, L. C. de P.; Sugamosto, M. L.; Lima, V. C. Avaliação da metodologia utilizada na geração dos mapas de fragilidade ambiental em uma área piloto na APA do Iraí. In: IV Seminário do Projeto Interdisciplinar sobre Eutrofização de Águas de Abastecimento Público na Bacia do Altíssimo Iguaçu, Curitiba-PR, 2003. 
Ross, J. L. S. Análise empírica da fragilidade dos ambientes naturais e antropizados. In: Revista do departamento de geografia, no 8. FFLCH. USP. São Paulo. 1994.

Santos, C. A.; Sobreira, F. G. Análise morfométrica como subsídio ao zoneamento territorial: o caso das bacias do Córrego Carioca, Córrego do Bação e Ribeirão Carioca na região do Alto Rio das Velhas - MG. Revista Escola de Minas, v.61, p.77-85, 2008.

SPÖRL, C.; ROSS, J. L. S. Análise comparativa da fragilidade ambiental com aplicação de três modelos. GEOUSP - Espaço e Tempo, São Paulo, n. 15, p.39-49, 2004.

Tricart, J. Ecodinâmica. Rio de Janeiro: IBGE - SUPREN, 1977.

VILLELA, S.M.; MATTOS, A. Hidrologia aplicada. McGraw-Hill do Brasil, São Paulo, 1975, p.245. 